\title{
Altered Neurogranin Phosphorylation and Protein Levels Are Associated with Anxiety- and Depression-Like Behaviors in Rats Following Forced Swim Stress
}

\author{
Huanhuan Li1 ${ }^{12}$, Wenjuan Lin ${ }^{*}$, Junfa Li ${ }^{3}$, Weiwen Wang1 \\ ${ }^{1}$ Brain-Behavior Research Center, Institute of Psychology, Chinese Academy of Sciences, Beijing, China \\ ${ }^{2}$ Department of Psychology, Renmin University of China, Beijing, China \\ ${ }^{3}$ Department of Neurobiology, Capital University of Medical Sciences, Beijing, China \\ Email: ${ }^{*}$ Linwj@psych.ac.cn
}

Received 13 September 2014; revised 28 October 2014; accepted 13 November 2014

Copyright (C) 2014 by authors and Scientific Research Publishing Inc.

This work is licensed under the Creative Commons Attribution International License (CC BY).

http://creativecommons.org/licenses/by/4.0/

(c) (i) Open Access

\begin{abstract}
Here we tested the hypothesis that stress-induced alterations in Neurogranin (Ng) synthesis and/ or utilization might underlie stress-related depression and anxiety. Rats were randomly divided into five conditions: chronic swim stress (CS), acute swim stress (AS), and three control groups. The CS group was exposed to daily swim stress ( $5 \mathrm{~min} /$ day) for 14 consecutive days, the AS group received a single swim stress, and control groups were maintained in a stress-free condition. Both before and after swim stress, rats were tested for body weight gain, open-field locomotor activity, and saccharine preference. $\mathrm{Ng}$ and phospho- $\mathrm{Ng}(\mathrm{P}-\mathrm{Ng}$ ) levels in the hippocampus and prefrontal cortex were determined by Western blot analysis. Compared to controls, CS animals displayed significantly decreased body weight gain, ambulation, and saccharine intake, and increased grooming behavior. CS animals had decreased $\mathrm{Ng}$ levels in the hippocampus and prefrontal cortex. In CS animals, $\mathrm{Ng}$ levels were positively correlated with saccharine intake and ambulation, and inversely correlated with grooming behavior. Compared to controls, AS increased immobility behavior and P-Ng and Ng levels in the hippocampus and prefrontal cortex. In AS animals, immobility behavior was positively correlated with the P-Ng in the prefrontal cortex. Thus, CS and AS produced opposing effects on $\mathrm{Ng}$ and P-Ng levels in the hippocampus and prefrontal cortex. Low $\mathrm{Ng}$ levels in the hippocampus were associated with anhedonic behavior in CS animals, whereas high P-Ng levels in the prefrontal cortex were associated with anxiety-like behavior in AS animals. Thus, $\mathrm{Ng}$ dysfunction might contribute to the neural mechanisms underlying stress-induced depression and anxiety.
\end{abstract}

${ }^{*}$ Corresponding author.

How to cite this paper: Li, H.H., Lin, W.J., Li, J.F. and Wang, W.W. (2014) Altered Neurogranin Phosphorylation and Protein Levels Are Associated with Anxiety- and Depression-Like Behaviors in Rats Following Forced Swim Stress. Journal of Behavioral and Brain Science, 4, 506-522. http://dx.doi.org/10.4236/jbbs.2014.411050 


\section{Keywords}

\section{Stress, Neurogranin, Hippocampus, Prefrontal Cortex, Anxiety, Depression, Rats}

\section{Introduction}

Stress is a major etiological factor in the development of human emotional disorders, including depression and anxiety [1] [2]. Animal models are frequently used to investigate the mechanisms underlying stress-related depression and anxiety. These models have now established various behavioral indices of animal depression and anxiety [1] [3] [4]. For example, hedonic deficit, defined as the lack of pleasure from sweet substance intake, is considered a rat depression-like behavior. Fear-induced immobility, on the other hand, is considered a rat behavior analogous to human anxiety [2].

One important issue in stress research is to understand how stress signals in the brain result in behavioral disorders. Neurotransmission, kinase-dependent postsynaptic signal transduction, and synaptic plasticity all have been implicated in mediating behavioral responses to stress [5]-[11]. Given the importance of brain-specific proteins for intracellular signal transduction, many stress studies over the last few years have focused on proteins involved in the growth, survival, and function of neurons [12]-[15]. For example, heat-shock protein 70 (HSP-70) plays a protective role in various models of nervous system injury [12] [15]. Abnormal functioning and/or disrupted synthesis of many proteins is associated with stress: HSP-70, brain derived neurotrophic factor (BDNF), cAMP responsive element binding protein (CREB), and growth associated protein 43 (GAP-43), all contribute to an altered stress response; some changes in the expression of these proteins have been implicated in neuropsychiatric disorders, including major depression [12] [13] [16].

Located postsynaptically, Neurogranin (Ng) is a calcium $\left(\mathrm{Ca}^{2+}\right)$ calmodulin (CaM) binding protein and protein kinase C (PKC) substrate. Ng is highly expressed in neurons within the prefrontal cortex, hippocampus, and amygdala: brain regions likely involved in stress and emotion responses [17] [18]. Because of its critical role in regulating neuronal $\mathrm{Ca}^{2+} / \mathrm{CaM}, \mathrm{Ng}$ has been implicated in numerous postsynaptic signal transduction pathways [19] [20]. In addition to being a PKC substrate, $\mathrm{Ng}$ also is a crucial substrate for $\mathrm{Ca}^{2+} / \mathrm{CaM}$-dependent protein kinase II (CaMKII) [21]. PKC and CaMKII have been implicated in learning and memory and in stress responses, likely via their ability to modulate gene expression, ion channel conductance, neurotransmission, and synaptic plasticity [22] [23].

Enhanced phosphorylation of Ng can facilitate N-methyl-D-aspartate (NMDA) receptor-dependent long-term potentiation (LTP) [24]. Accumulating evidence suggests that Ng has a vital role in aging [14], neurodegenerative diseases [25], learning and memory [26], opioid tolerance and dependence [27], and schizophrenia [28]. As a consequence of attenuated PKC-dependent signal transduction and NMDA receptor-dependent LTP, Ng knockout mice exhibit markedly decreased hippocampal-dependent spatial learning and memory, and increased anxiety responses to a novel environment [26]. Mice lacking Ng exhibit decreased PKC activation and CaMKII autophosphorylation [20] [29]; thus, Ng phosphorylation and activation may serve as a mechanism for synchronizing PKC and CaMKII activity [29]. Ng therefore appears to have a central role in mediating the behavioral response to stress through its actions on kinase-dependent signal transduction pathways, neurotransmission, and synaptic plasticity.

The role of $\mathrm{Ng}$ in stress and stress-related behavioral changes, however, is not clearly defined. In experimental animals, acute sleep deprivation decreased $\mathrm{Ng}$ levels in the cerebral cortex, but did not change Ng levels in the hippocampus [30]. Acute electroconvulsive seizure decreased both Ng and PKC protein levels and phosphorylation in the hippocampus [31], and restraint stress also decreased Ng expression in the hippocampus [32]. These findings clearly suggest that stress affects Ng protein levels and Ng signaling pathways; importantly, however, these aforementioned studies did not quantify behavioral parameters. Given the above evidence, we hypothesize that $\mathrm{Ng}$ not only is involved in the response to stress, but also is involved in the pathophysiology of stress-induced emotional disorders. Thus, Ng may represent a significant target for understanding the neural mechanisms of stress-related depression and anxiety.

It is well established that the hippocampus and prefrontal cortex are essential components of the neural circuitry mediating stress [33]. Chronic stress affects neurons in the hippocampus and prefrontal cortex in a variety 
of ways including alterations in dendritic morphology, cell survival, and neurogenesis. Chronically stressed rats exhibit decreased hippocampal volume and prefrontal cortex dysfunction: alterations thought to be involved in depression pathogenesis [34] [35]. Clinical magnetic resonance imaging studies have demonstrated that patients with major depression show hippocampal neuronal atrophy and prefrontal cortex dysfunction [36]. The molecular mechanisms underlying the effects of stress in the hippocampus and prefrontal cortex, however, remain unclear.

In the present study, we examined the effects of either single or repeated swim stress on behavior and Ng levels in rats. A variety of behavioral parameters (i.e., grooming, exploratory events, immobility, and saccharine intake) were assessed using open field locomotor activity and saccharine preference tests. We hypothesized: 1) CS significantly induces depression-like behaviors, while AS induce anxiety-related behaviors; 2) CS and AS may produce opposite effects on brain levels of $\mathrm{Ng}$ and $\mathrm{P}-\mathrm{Ng}$ in prefrontal cortex and hippocampus, with decrement in the former situation and enhancement in the latter; 3) Changes in Ng and P-Ng levels in the selected brain regions would be strongly associated with the stress-related behavioral changes. The forced swim stress test (i.e., a paradigm of behavioral despair; FST) is a putative animal model of depression. Consequently, the FST is one of the most frequently used methods for investigating antidepressant potential [2]. Although the behavioral and physiological responses to the FST have been most widely studied in the context of chronic stress, the effects of a single exposure to stress are noteworthy to clarify the physical and psychological consequences for the acute stress procedure [37].

\section{Material and Methods}

\subsection{Animals and Housing}

Male Sprague-Dawley rats weighing 276 to $338 \mathrm{~g}$ at the beginning of the experiment were obtained from Wei Tong Li Hua Lab Animal Center (Beijing, China). Rats were individually housed in cages $\left(25 \times 25 \times 15 \mathrm{~cm}^{3}, \mathrm{~L}\right.$ $\times \mathrm{W} \times \mathrm{H})$ in a temperature and humidity controlled $\left(22^{\circ} \mathrm{C} \pm 2^{\circ} \mathrm{C}\right.$; relative humidity of $\left.50 \%\right)$ facility on a 12-h light cycle (lights on 08:00 h). To minimize the stressful effects of handling, rats were acclimated to the laboratory and gently handled daily ( $3 \mathrm{~min} /$ day) for seven days prior to testing. Food and water were provided ad libitum at all times except during the saccharine preference test. Fifty rats were randomly assigned to one of five groups ( $n=10$ /group): chronic swim stress (CS), acute swim stress (AS), control 1 (C1), control 2 (C2), and control 3 (C3). Rats in the CS group were forced to swim individually for 5 min per day for 14 consecutive days. Rats in the AS group were forced to swim individually for 5 min on a single occasion. Rats in the C1 group received behavioral tests but no swimming stress during chronic swimming stress period. Rats in the C2 group received behavioral tests but no swimming stress during acute swimming stress period. Rats in the C3 group remained experimentally naive to control for the possible effects of behavioral testing on $\mathrm{Ng}$ levels. Rats in the CS, AS, C1, and C2 groups were tested for open-field locomotor activity and saccharine preference both before (baseline) and after (stress effects) swim stress. All experiments were performed in a sound-shielded room under identical conditions. The International Review Board of the Institute of Psychology, Chinese Academy of Sciences, approved all experimental procedures. All the behavioral procedures in a time line were shown in Figure 1.

\subsection{Stress Procedure}

According to previously described methods [38], forced swim trials occurred during the light phase (08:00 $\mathrm{h}$ to 10:00 h) in a stainless steel tank $\left(2.0 \times 1.0 \times 1.5 \mathrm{~m}^{3}, \mathrm{~L} \times \mathrm{W} \times \mathrm{H}\right)$. During the swim test, the room was illuminated by a single $40 \mathrm{~W}$ dim light bulb suspended and water in the tank was maintained at a height of $30 \mathrm{~cm}$ and $10^{\circ} \mathrm{C}$. At the end of each swim trial, animals were towel dried and placed under an incandescent heat lamp for 10 min before being returned to their home cage.

\subsection{Body Weight}

Rats were weighed on the $1^{\text {st }}$ and $7^{\text {th }}$ day of handling, and on the $1^{\text {st }}, 7^{\text {th }}$, and $14^{\text {th }}$ day of swimming stress. Body weight after handling (CWT), the first $7^{\text {th }}$ day of swimming stress (SWT7), and $14^{\text {th }}$ day of swimming stress (SWT14) were recorded. 


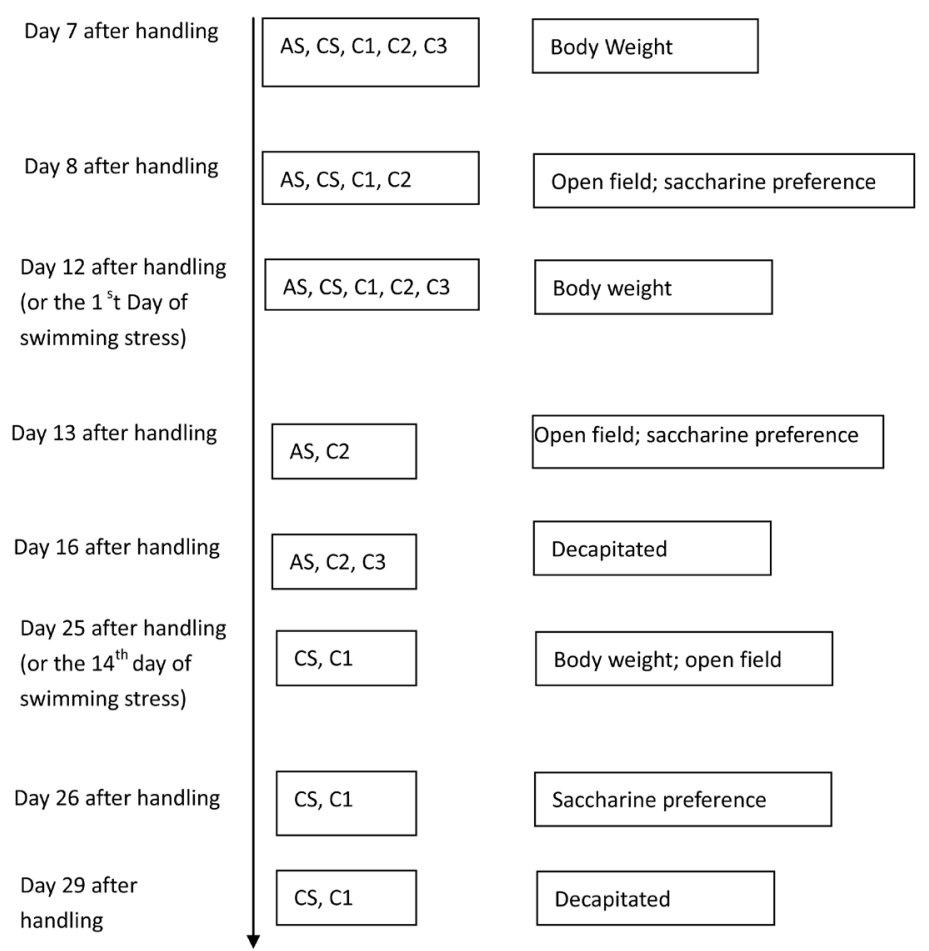

Figure 1. All the behavioral procedures for the five groups are in a time line.

\subsection{Behavioral Tests}

\subsubsection{Open Field Locomotor Activity}

Open field locomotor activity testing was performed on day 8 after handling (baseline, four groups), and on the $1^{\text {st }}$ (AS and C2 group) and $14^{\text {th }}$ day (CS and C1 group) after swimming stress between 08:00 $\mathrm{h}$ and 12:00 $\mathrm{h}$ in a $180 \mathrm{~cm}$ diameter round arena with $50 \mathrm{~cm}$ high walls. A dim light $(40 \mathrm{~W})$ was used in the open field testing room to decrease the likelihood that the test would be aversive for the rats. Individual rats were placed near the wall of the chamber and the following variables were recorded by an automatic infrared behavioral analysis system (Etho Vision, Noldus Information Technology b.v., Netherlands): ambulation (distance traveled), number of rearing events (standing on the hind legs), number of grooming events (rubbing or licking of the body), number of exploratory events (entering the center zone of the open field), and immobility (motionless posture for 5 seconds). Data were collected for $5 \mathrm{~min}$ and analyzed by a computer-based system. At the end of each test, animals were removed and returned to their home cages.

\subsubsection{Saccharine Preference}

Saccharine preference test were performed on day 8 after handling (baseline, four groups), and on the $1^{\text {st }}$ (AS and C2 group) and $14^{\text {th }}$ day (CS and C1 group) after swimming stress. Rats were water deprived overnight (20:00 $\mathrm{h}$ to $08: 00 \mathrm{~h}$ ) the day before saccharine preference testing. From that point onward, rats were exposed for $3 \mathrm{~h}$ each day to two bottles: one bottle contained tap water and the other bottle contained a $1 \%$ saccharine solution. Preference testing was performed $8 \mathrm{~h}$ into the light phase on 4 consecutive days. Total saccharine, water, and fluid (saccharine + water) intake was calculated for the sums of four days of testing. A chronic stress-induced reduction of saccharine consumption is considered a measure of anhedonia and we used this definition here. Saccharine and water bottle positions in the cages were alternated daily. At the end of preference testing, rats were returned to ad libitum water access.

\subsection{Western Blot}

\subsubsection{Materials}

Phospho-specific Ng (P-Ng; mouse polyclonal; 1:1000) and Ng primary antibodies (rabbit monoclonal; 1:1000) 
were obtained from Upstate Biotechnology (Lake Placid, NY) and $\beta$-actin primary antibody (mouse monoclonal; 1:1000) was obtained from Sigma-Aldrich (St. Louis, MO). Horseradish peroxidase (HRP)-labeled goat antirabbit and HRP-labeled goat anti-mouse secondary antibodies were obtained from Sigma-Aldrich. Nitrocellulose blotting membranes $(0.2 \mu \mathrm{m})$, polyacrylamide gels, and buffers also were obtained from Sigma-Aldrich. Bicinchoninic acid (BCA) protein assay and enhanced chemiluminescence (ECL) reagents were obtained from Pierce Biotechnology (Rockford, IL). The Gel Doc ${ }^{\mathrm{TM}}$ XR System and Quantity One 1D analysis software were purchased from Bio-Rad (Hercules, CA).

\subsubsection{Tissue Dissection and Sample Preparation}

Immediately after the first swim stress and behavioral tests (day 12 after handling), rats in the AS, C2, and C3 groups were decapitated on day 16 after handling (or the following day after the second saccharine preference test is over), whereas rats in the CS and C1 groups were decapitated after the final swim stress and behavioral tests on day 29 after handling (or the following day after the second saccharine preference test is over). Brains were rapidly removed on ice. The brain was placed in a stainless steel brain matrix and the prefrontal cortex and whole body of hippocampus were removed according to a brain atlas [39]. All tissues were immediately flash frozen with liquid nitrogen.

Tissue samples were homogenized in 20 volumes of buffer (50 mM Tris-Cl, 2 mM EDTA, 2 mM EGTA, 0.05 $\mathrm{mM}$ okadaic acid, $1 \mu \mathrm{M}$ sodium vanidate, $5 \mu \mathrm{g} / \mathrm{ml}$ pepstatin $\mathrm{A}$, and $0.5 \%$ Nonidet $\mathrm{P}-40, \mathrm{pH}$ 7.5) and used for protein and immunoblot analyses [29]. Protein concentration was determined using a BCA protein assay. Lysates were mixed with $5 \mathrm{X}$ sodium dodecyl sulfate (SDS) and resuspended at predetermined concentrations ( $2 \mu \mathrm{g} / \mu \mathrm{l})$. All samples were stored at $-70^{\circ} \mathrm{C}$.

\subsubsection{Protein Separation and Immunoblot Analysis}

Proteins were separated by SDS-polyacrylamide gel electrophoresis in a 15\% denaturing gel and then transferred to NC using an electroblotting transfer system. Blots were incubated with blocking buffer $[10 \%$ nonfat dry milk in Tris-buffered saline containing $0.5 \%$ Tween-20 (TBST)] for $1 \mathrm{~h}$ at room temperature, followed by three 10-min washes in TBST. Blots were then incubated with P-Ng primary antibody $16-18$ hours at $4^{\circ} \mathrm{C}$, followed by three 10-min washes in TBST. P-Ng labeled blots were then incubated with goat anti-rabbit secondary antibody for $1 \mathrm{~h}$ at room temperature. Following secondary application, blots were washed three times for 10 min each in TBST, treated with ECL reagents, and exposed to film. After determination of P-Ng immunoreactivity, blots were stripped of antibodies by a 10 -min incubation at $50^{\circ} \mathrm{C}$ with stripping buffer (50 mM DTT, 3\% SDS, and $62.5 \mathrm{mM}$ Tris-HCl, $\mathrm{pH}$ 6.8) [20]. Stripped blots were then blocked and washed as described above, followed by a 3-h incubation at room temperature with Ng primary antibody. Ng-labeled blots were then incubated with secondary antibody and visualized as described above. Determination of $\beta$-actin followed the same methods described for $\mathrm{Ng}$, except that $\beta$-actin blots were not stripped and we used a goat anti-mouse secondary antibody.

The intensity of protein bands was determined using Quantity One 1D analysis software. The intensities of $\mathrm{P}-\mathrm{Ng}, \mathrm{Ng}$, and $\beta$-actin all were within the linear range of sensitivity of the scanner. $\beta$-actin was used as an internal standard. All P-Ng and Ng blots were normalized to $\beta$-actin to correct for small differences in protein loading [27].

\subsection{Statistical Analysis}

Statistical analyses were performed using the "Statistical Package for Social Sciences" option of SPSS, version 17.0 for Windows (Chicago, IL). All data are presented as mean values \pm S.E.M. The control and swim stress groups were compared using the Mann-Whitney $\mathrm{U}$ test for 2 samples and the Kruskal-Wallis one-way ANOVA for $\mathrm{k}$ samples. The relationship of proteins and behavioral responses was determined using Pearson correlation analysis. The level of statistical significance was set at $p<0.05$.

\section{Results}

\subsection{Body Weight}

Body weight did not differ significantly between control and stress groups on the $7^{\text {th }}$ day of handling; after the 
$1^{\text {st }}$ day of swimming stress, there are no significant differences between AS, C2 and C3 group; after seven days of stress, however, CS rats showed less body weights than the C1 group (340.53 $\pm 10.10 \mathrm{~g}$ vs. $365.90 \pm 7.26 \mathrm{~g}$, respectively; $z=-1.96, p<0.05$ ). This difference persisted after 14 days of stress, when body weights of CS rats were markedly less than those of the C1 group (333.47 $\pm 9.37 \mathrm{~g}$ vs. $376.53 \pm 9.05 \mathrm{~g}$, respectively; $z=-2.77, p<$ 0.01; Figure 2 and Figure 3).

\subsection{Open Field Locomotor Activity}

Baseline behavioral parameters (ambulation, number of rearing, number of grooming, number of exploration, and immobility time) were not significantly different between C1, C2, AS and CS group $\left[X^{2}=3.51, p>0.05 ; X^{2}\right.$ $\left.=2.49 ; p>0.05 ; X^{2}=1.93, p>0.05 ; X^{2}=1.40, p>0.05 ; X^{2}=3.33, p>0.05\right]$ on the $7^{\text {th }}$ day of handling. After the $1^{\text {st }}$ day of swim stress, rats in the AS group showed increased immobility time compared to rats in the C2 group (35.15 $\pm 14.75 \mathrm{~s}$ vs. $3.00 \pm 3.00 \mathrm{~s}$, respectively; $z=-2.10, p<0.05$; Figure 4). There were no significant differences in the other variables between AS and the C2 group (ambulation: $z=-0.76, p>0.05$; number of rearing: $z=0.01, p>0.05$; number of grooming, $z=-1.04, p>0.05$; number of exploration: $z=0.01, p>0.05$ ).

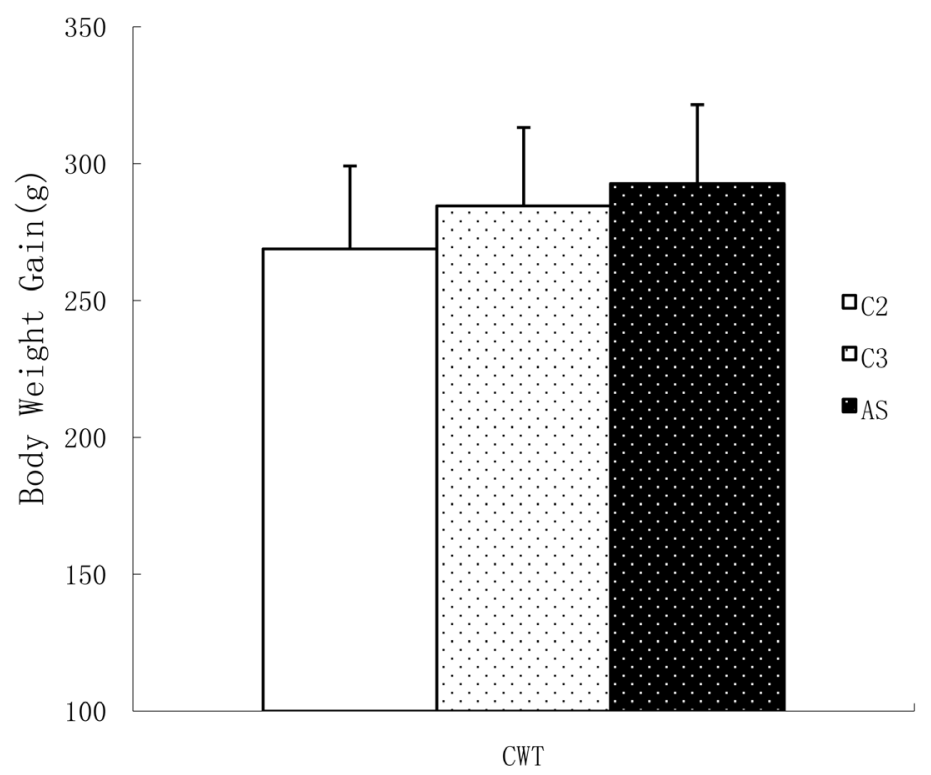

Figure 2. Body weight of the C2, C3 and AS group on the $7^{\text {th }}$ handling days (CWT). All data were presented as mean \pm S.E.M. $N=10$ per group.

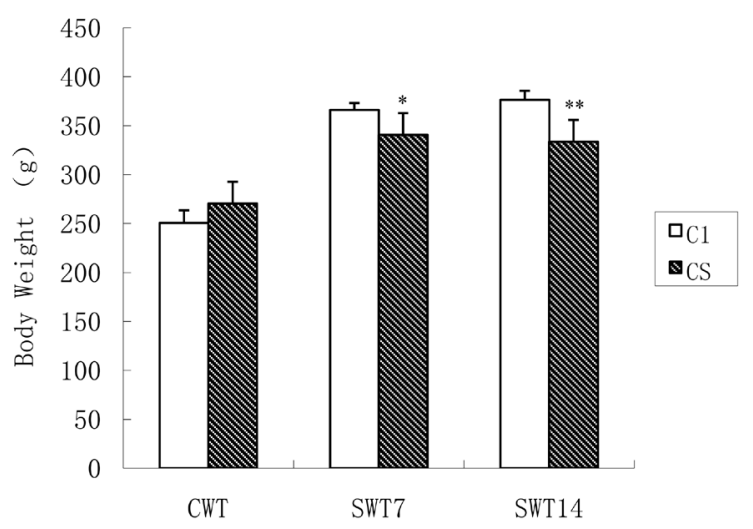

Figure 3. Body weight of the C1 group and CS group on the $7^{\text {th }}$ day of handling (CWT), the $7^{\text {th }}$ day of stress (SWT7) and $14^{\text {th }}$ day of stress (SWT14). All data were presented as mean \pm S.E.M. $N=10$ per group. ${ }^{*} p<0.05$; ${ }^{* *} p<$ 0.01 . 


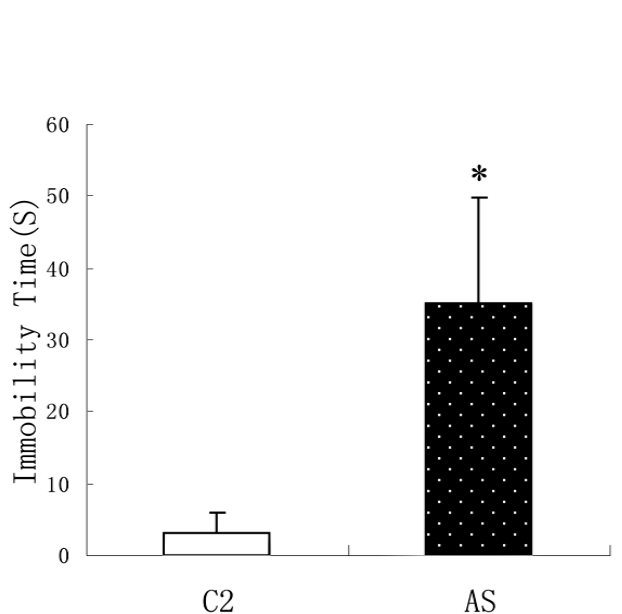

(a)

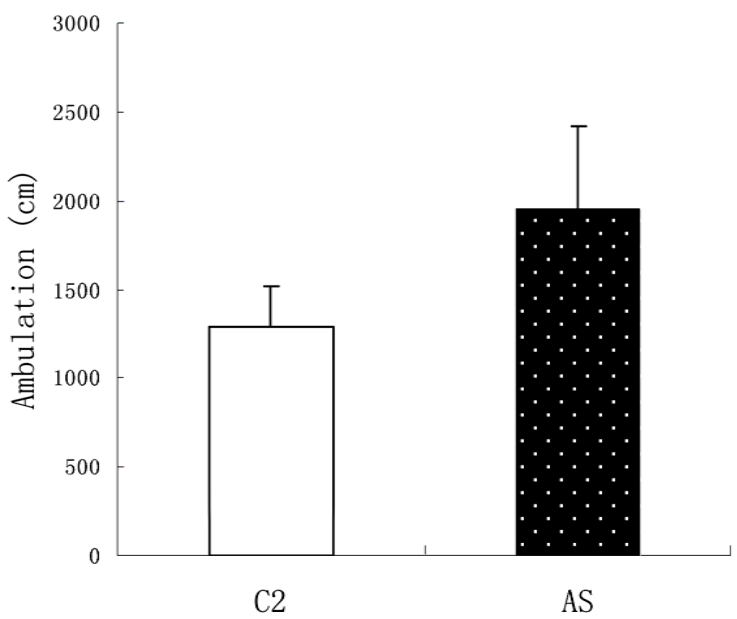

(c)

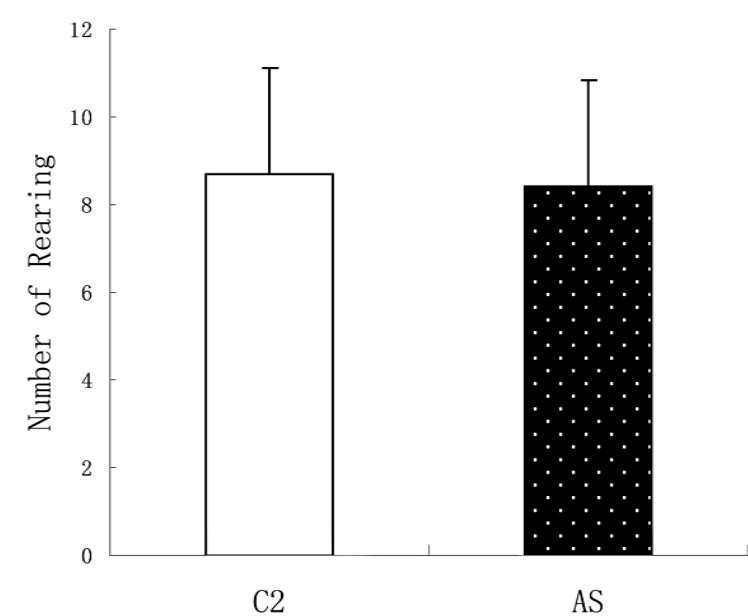

(b)

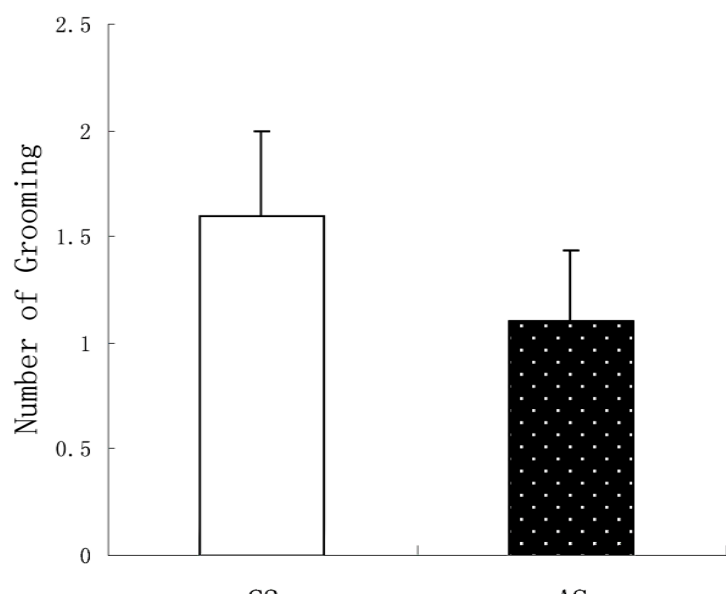

$\mathrm{C} 2$

Figure 4. Behavioral measures of the C2 and AS group in open field. (a) Immobility time: AS animals showed more freezing time than the C2 group; (b) Number of rearing; (c) Ambulation distance; (d) Number of grooming. All data were presented as mean \pm S.E.M. $N=10$ per group. ${ }^{* *} p<0.01$.

After 14 days of stress, rats in the CS group showed less ambulation and more grooming behavior compared to rats in the C1 group (ambulation $=2221.86 \pm 323.82 \mathrm{~cm}$ vs. $3230.57 \pm 299.56 \mathrm{~cm}$, respectively; $z=-2.208, p$ $<0.05$; number of grooming $=2.60 \pm 0.31$ vs. $1.33 \pm 0.24$, respectively; $z=-2.66, p<0.01$; Figure 5 ). There were no significant differences in the other variables between CS and the C1 group (number of rearing: $z=$ $-0.67, p>0.05$; number of exploration: $z=-0.67, p>0.05$; immobility time: $z=-0.92, p>0.05$ ).

\subsection{Saccharine Preference Test}

Baseline total sum of saccharine intake $\left(X^{2}=2.19 ; p>0.05\right)$, water intake $\left(X^{2}=0.08 ; p>0.05\right)$ and total fluid intake $\left(X^{2}=0.32 ; p>0.05\right)$ for four days during the test period did not differ significantly between control and stress groups after day 7 of handling. Similarly, saccharine $\left(X^{2}=-1.50 ; p>0.05\right)$, water $\left(X^{2}=-0.23 ; p>0.05\right)$, and total fluid intake $\left(X^{2}=-0.57 ; p>0.05\right)$ was not significantly different between the AS group and C2 group following the first swim stress. After 14 days of stress, rats in the CS group consumed less saccharine than rats in the $\mathrm{C} 1$ group ( $39.47 \pm 7.48$ vs. $59.48 \pm 6.15$ g, respectively; $z=-2.27, p<0.05$ ). There were no significant differences in water or total fluid intake between the CS and C1 groups (water $=72.92 \pm 7.60 \mathrm{~g}$ vs. $68.50 \pm 7.75$ g, respectively; $\mathrm{z}=-0.23, p>0.05$; total liquids $=112.39 \pm 8.50 \mathrm{~g}$ vs. $127.98 \pm 6.20 \mathrm{~g}$, respectively; $\mathrm{z}=-1.36$, $p>0.05$; Figure 6). 


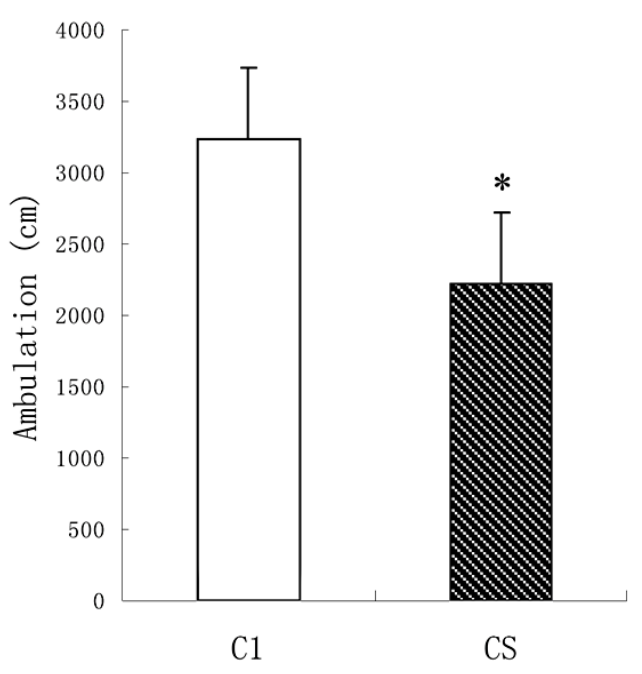

(a)

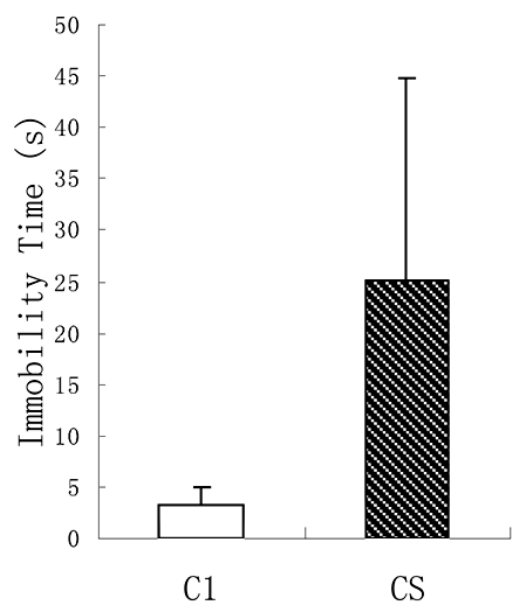

(c)

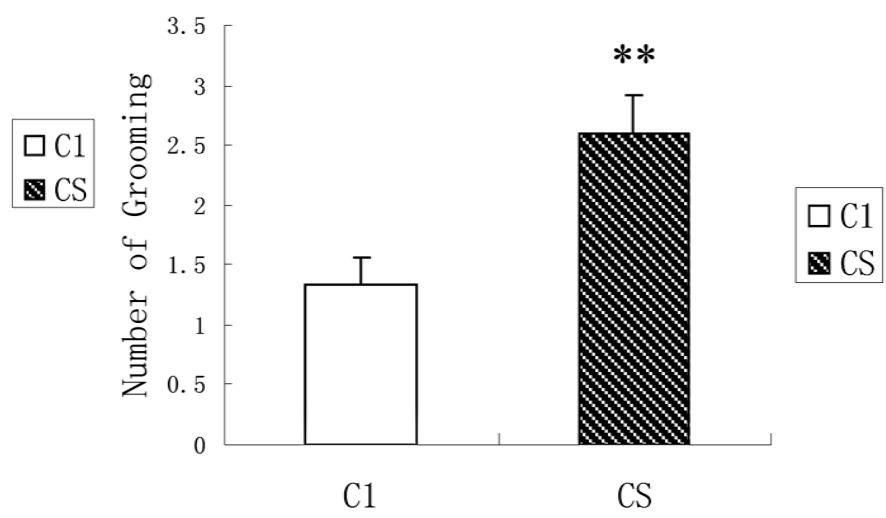

(b)

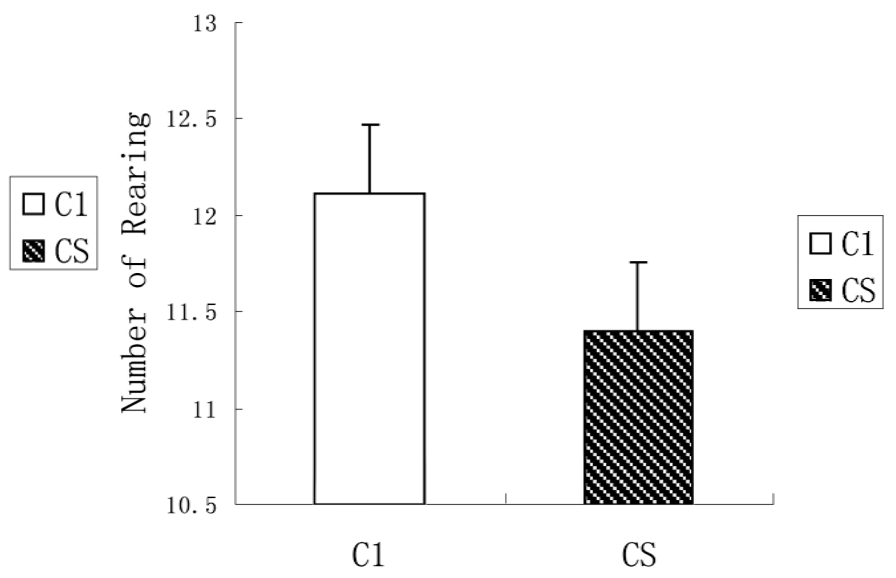

(d)

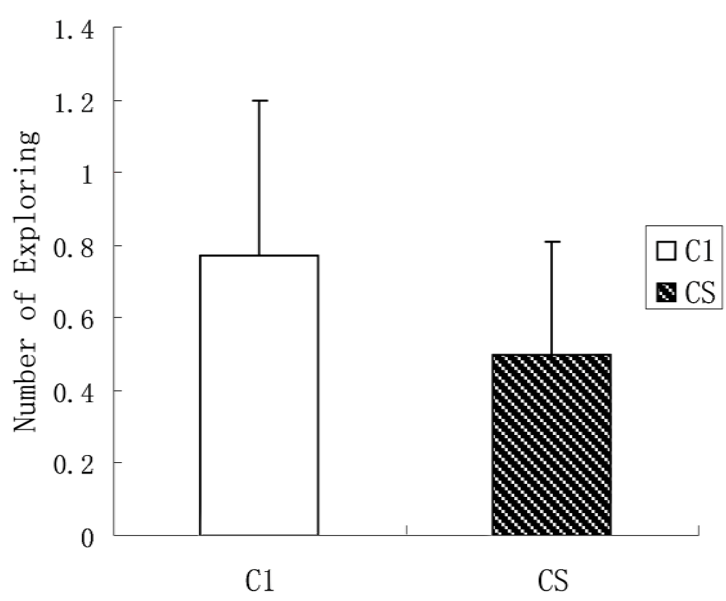

(e)

Figure 5. Behavioral measures of the C1 and CS group in open field. (a) Ambulation distance: CS animals showed less ambulation distance than the C1 group; (b) Number of grooming: CS animals showed more grooming behavior as compared to the C1 group; (c) Immobility time; (d) Number of rearing; (e) Number of exploring. All data were presented as mean \pm S.E.M. $N=10$ per group. ${ }^{*} p<0.05 ;{ }^{* *} p<0.01$. 


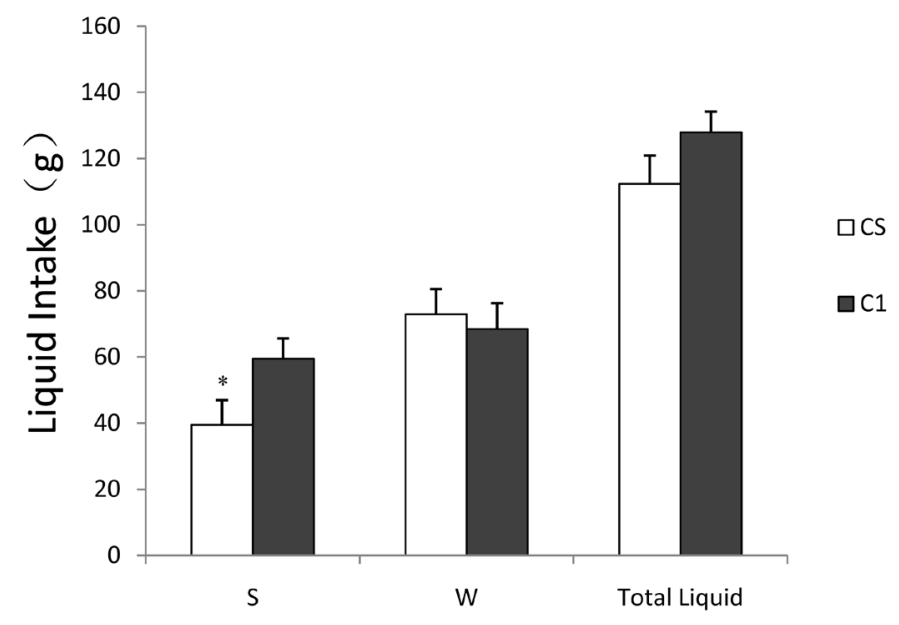

Figure 6. Saccharine preference of the $\mathrm{C} 1$ group and CS group. The saccharine solution intake (S), water intake (W) and the total liquids (saccharine solution + water) intake in 4 days. All data were presented as mean \pm S.E.M. $N=10$ per group. ${ }^{*} p<0.05$.

\subsection{P-Ng and Ng Levels in the Hippocampus and Prefrontal Cortex}

On Western blot, P-Ng was detected as a $20 \mathrm{kDa}$ band, Ng was detected as a $17 \mathrm{kDa}$ band, and $\beta$-actin was detected as $42 \mathrm{kDa}$ band [27]. AS rats had higher P-Ng expression than rats in the C2 group in both the hippocampus and prefrontal cortex (hippocampus: $64.27 \% \pm 10.13 \%$ vs $46.47 \% \pm 3.83 \%$, respectively; $z=-2.38, p<$ 0.05 ; prefrontal cortex: $69.64 \% \pm 9.32 \%$ vs. $41.02 \% \pm 4.81 \%$, respectively; $z=-2.834, p<0.01$ ) and higher $\mathrm{P}-\mathrm{Ng}$ levels in the hippocampus than rats in the C3 group (64.27\% $\pm 10.13 \%$ vs. $45.52 \% \pm 5.37 \%$, respectively; $z=-2.43, p<0.05$ ). In both the hippocampus and prefrontal cortex, Ng levels in the AS group were much more than the C2 group (hippocampus: $243.66 \% \pm 49.38 \%$ vs. $166.77 \% \pm 13.77 \%$, respectively; $z=-2.03, p<0.05$; prefrontal cortex: $254.67 \% \pm 33.93 \%$ vs. $171.67 \% \pm 14.84 \%$, respectively; $z=-2.00, p<0.05$ ) and the C3 group (hippocampus: $243.66 \% \pm 49.38 \%$ vs. $148.17 \% \pm 22.04 \%$, respectively; $z=-2.59, p<0.01$; prefrontal cortex: $254.67 \% \pm 33.93 \%$ vs. $136.68 \% \pm 11.46 \%$, respectively; $z=-3.02, p<0.01$; Figure 7 and Figure 8 ). $\mathrm{P}-\mathrm{Ng}$ and $\mathrm{Ng}$ were not significantly different between the C2 and C3 group.

In the hippocampus and prefrontal cortex, CS rats had less $\mathrm{Ng}$ levels than rats in the $\mathrm{C} 1$ group (hippocampus: $99.54 \% \pm 7.82 \%$ vs. $137.10 \% \pm 6.58 \%$, respectively; $z=-2.69, p<0.01$; prefrontal cortex: $74.55 \% \pm 5.92 \%$ vs. $143.29 \% \pm 15.31 \%$, respectively; $z=-2.68, p<0.01$ ). However, P-Ng levels were too weak to be detected in the hippocampus and prefrontal cortex of rats in the CS group (Figure 9 and Figure 10).

\subsection{Protein-Behavioral Correlations}

In AS animals, P-Ng in the prefrontal cortex was positively correlated with immobility $(r=0.50, p<0.05$; Figure 11). In CS animals, $\mathrm{Ng}$ in the hippocampus was positively correlated with saccharine intake $(r=0.53, p<$ $0.05)$ and ambulation $(r=0.57, p<0.05)$. An inverse correlation was also found between $\mathrm{Ng}$ in the hippocampus and grooming $(r=-0.64, p<0.01$; Figure 12).

\section{Discussion}

Environmental factors, such as stress, can impact the neurobehavioral profile of an organism and precipitate a depression-like syndrome. Here we determined the effects of single or repeated forced swim stress on behavioral and neurobiological responses in the rat. Interestingly, we found that chronic and acute forced swim stress produce qualitatively different effects on behavior and brain $\mathrm{Ng}$ levels.

\subsection{The Effects of Forced Swim Stress on Rat Behavior}

As previously reported [9], chronic exposure to forced swim stress disrupted body weight gain. When CS rats 


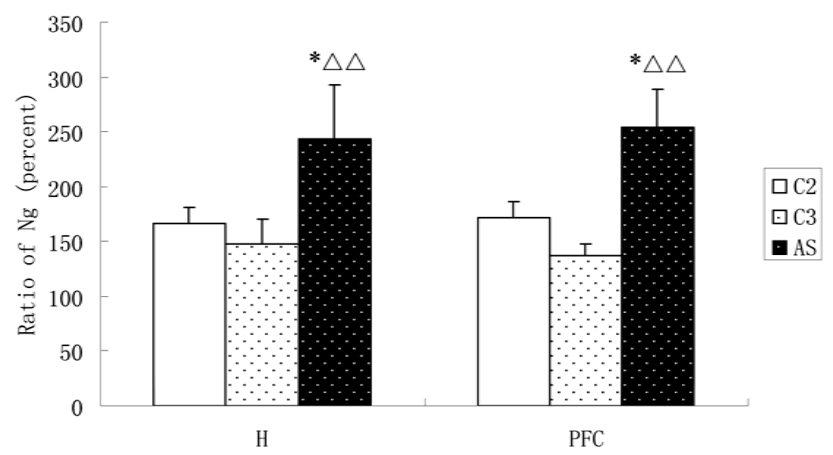

(a)

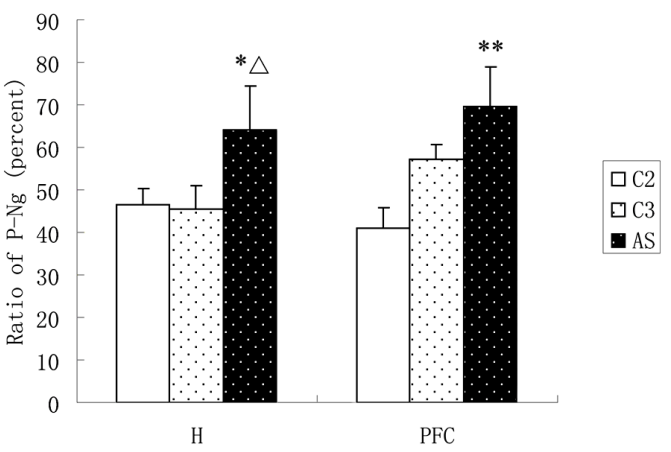

(b)

Figure 7. The Ng (a) and P-Ng (b) in the hippocampus and the prefrontal cortex. H, hippocampus; PFC, prefrontal cortex. All data were presented as mean \pm S.E.M. $N=10$ per group. ${ }^{*} p<0.05$ compared to C2 group; $* * p<0.01$ compared to C2 group; $\triangle p<0.05$ compared to C3 group; $\triangle \triangle p<0.01$ compared to C3 group.

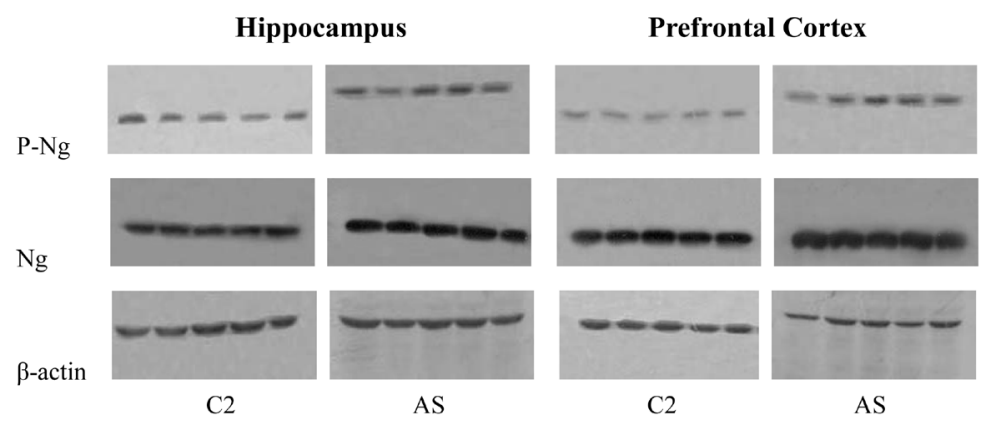

Figure 8. The P-Ng, $\mathrm{Ng}$ and $\beta$-actin in the hippocampus and prefrontal cortex. $\mathrm{C} 2$, control 2 group; AS, acute swim stress group.

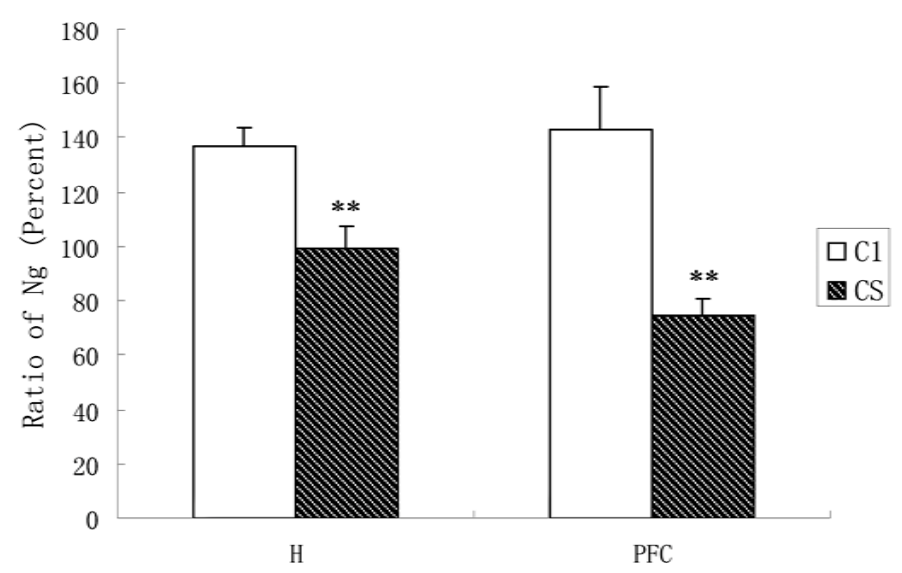

Figure 9. The Ng level in the hippocampus and the prefrontal cortex of the C1 group and CS group. $\mathrm{H}$, hippocampus; PFC, prefrontal cortex. All data were presented as mean \pm S.E.M. $N=10$ per group. $* * p<0.01$.

were exposed to 5-min of forced swim repeatedly for 14 days, their body weight gain was markedly less than that of control rats. This finding suggests that CS is a severe stressor and these rats were unable to physiological adapt to the situation. When compared to stress-naive rats, CS rats also demonstrated decreased ambulation and increased grooming in open field and decreased saccharine intake. In rats, a low preference for $1 \%$ saccharine, defined as hedonic deficit, is analogous to the core symptom of major depression in humans: namely, lack of pleasure [2]. The behavior of CS rats in our study is in accordance with previous findings [9] [37], and is very similar to symptoms of depressed patients: for example, weight loss, lack of pleasure, and low energy [6]. 


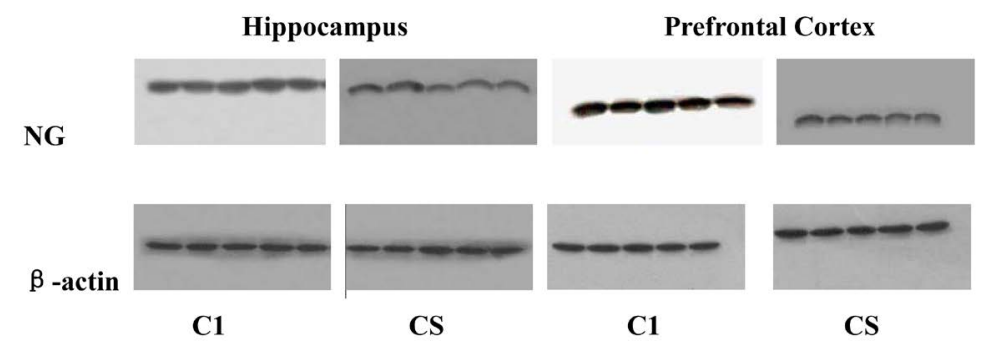

Figure 10. The $\mathrm{Ng}$ and $\beta$-actin in the hippocampus and prefrontal cortex. $\mathrm{C} 1$, control 1 group; CS, chronic swim stress group.

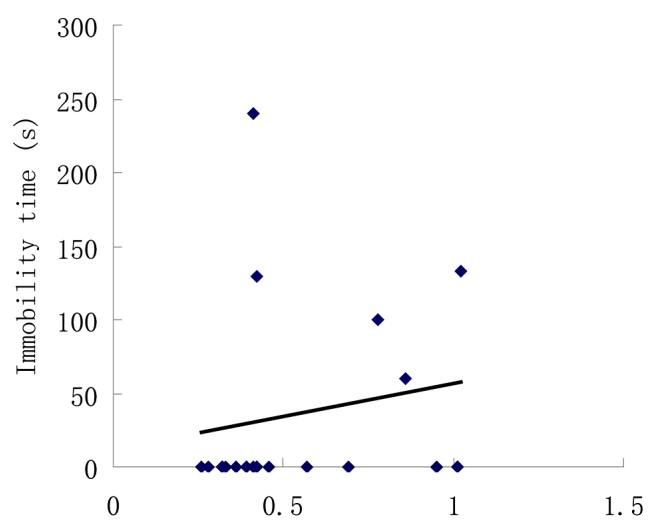

Figure 11. Correlation between the level of P-Ng in the prefrontal cortex and the immobility time. The P-Ng was positively correlated to the freezing time.

In rats, exploratory behavior in a novel environment is considered a stress-coping behavior [40], whereas selfgrooming induced by a novel environment is considered an index of emotional arousal [41]. Thus, decreased ambulation and increased grooming behavior are indices of anxiolytic activity. Stress, anxiety, and depression are interrelated phenomena [2]. Anxiety is not only accompanied by depression symptoms, but also may increase the likelihood of developing certain forms of depression [4]. Here we demonstrate that chronic exposure to swim stress induced depression-like behavior in rats, and that depression and anxiety overlapped in this animal model of depression.

Compared to stress-naive animals, a single forced swim stress experience increased rats' immobility in the open field test; this could be interpreted as a passive coping style [42]. Fear-like reactions in animals, such as immobility, are analogous to anxiety-related behavior in humans [2]. Whereas hedonic deficit was induced by chronic forced swim stress, it was not elicited by acute forced swim stress. Dal-Zotto and colleagues [37] have reported that rats exposed to chronic swim stress showed depression-like behaviors: in particular, very low levels of struggling and high levels of floating. Swimming-induced floating, however, was not found in rats exposed to acute swim stress [37]. Clinically, studies have demonstrated that chronic, but not acute, stress increases an individual's vulnerability to depression [43]. In the rats in our study, it appears that AS induced anxiety-like behavior, rather than depression-like behavior. The different behavioral effects produced by single and repeated forced swim stress suggest that these behaviors may be mediated by different neurobiological mechanisms.

\subsection{The Effects of Forced Swim Stress on Ng Levels in the Rat Brain}

Repeated exposure to swim stress for 14 days produced a marked reduction in Ng levels in the hippocampus and prefrontal cortex. Changes in Ng levels following repeated stress is in accordance with a previous study using chronic restraint stress [32]. Suppression of protein synthesis is considered a common cellular response to severe stress including physical stress, metabolic stress, or viral infection [14]. Chronic mild stress inhibits synthesis of brain-specific proteins, including BDNF and CREB [13]. Thus, the decreased Ng levels observed in our CS animals could be the result of inhibited Ng synthesis during the chronic stress period. 


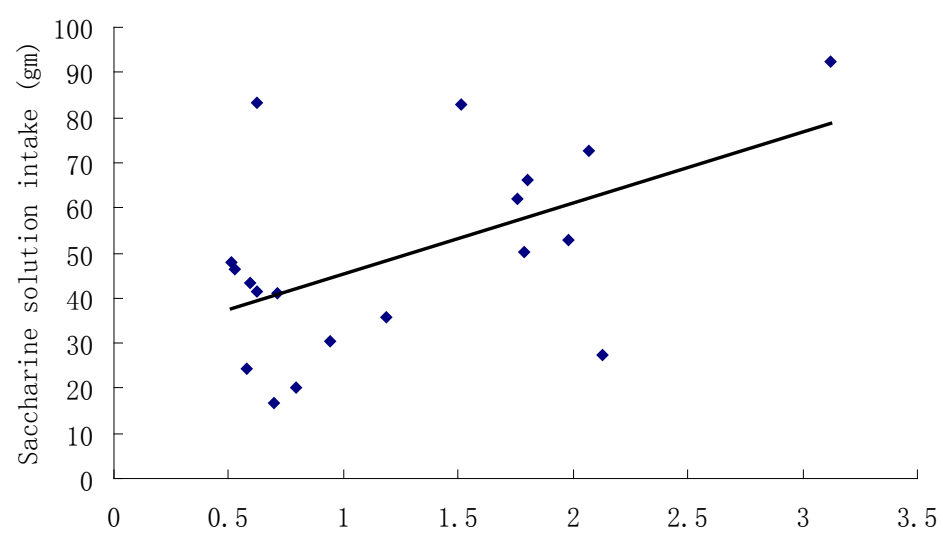

(a)

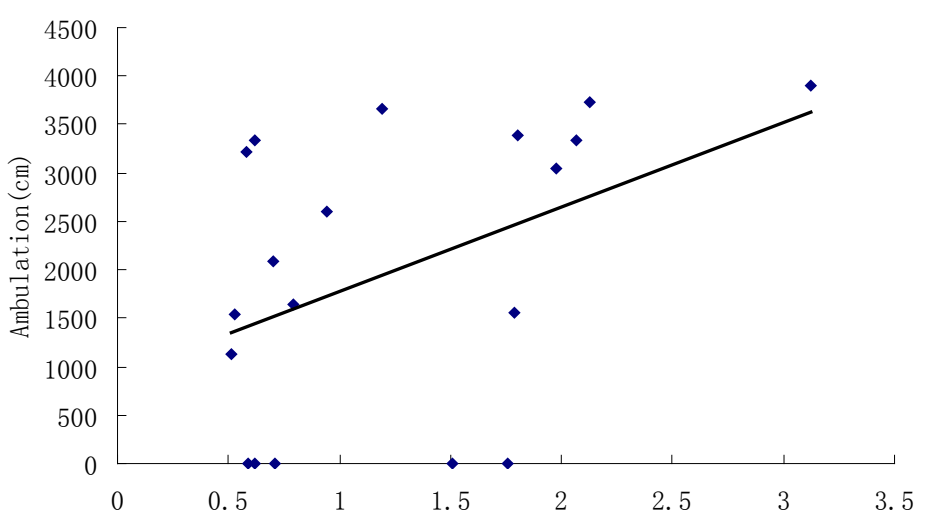

(b)

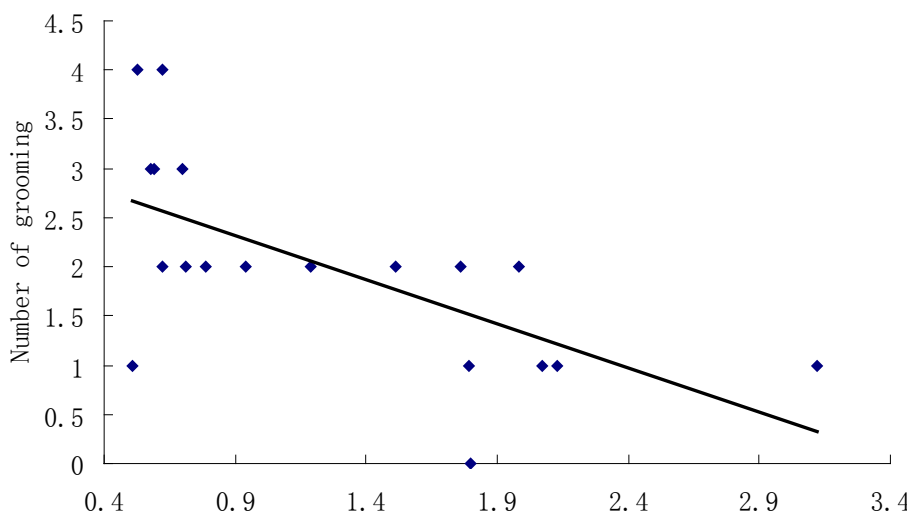

(c)

Figure 12. The Ng level in the hippocampus and the prefrontal cortex of the $\mathrm{C} 1$ group and CS group. H, hippocampus; PFC, prefrontal cortex. All data were presented as mean \pm S.E.M. $N=10$ per group. ${ }^{* *} p<0.01$.

P-Ng could not be detected in our CS animals. Qi and colleagues [9] found that phosphorylated extracellular signal-regulated kinase (ERK) 1 was too weak to be detected in the hippocampus and prefrontal cortex following exposure to chronic swim stress. Chen [31] interpreted a reduction in stress-induced P-Ng as a sign of deficient Ng utilization. Therefore, it is possible that the lack of P-Ng detection in our CS animals resulted from significantly decreased $\mathrm{Ng}$ phosphorylation.

Interestingly, AS produced the opposite effect of CS on Ng levels. Compared to stress-naive animals, AS increased $\mathrm{Ng}$ and P-Ng levels in the hippocampus and prefrontal cortex. These findings are in accordance with a 
study by Shen et al. [44], in which a single 15-min forced swim session increased P-ERK2 in the prefrontal cortex and neocortex. AS-induced increases in Ng and P-Ng, however, are in contrast to findings with other acute stressors. As previously mentioned, acute sleep deprivation decreased Ng levels in the cerebral cortex, but did not change Ng levels in the hippocampus [30]. Chen [31] reported that acute electroconvulsive seizure decreased Ng protein levels and phosphorylation in the hippocampus. These discrepancies could be explained by differences in the type and/or intensity of the stressors. Importantly, P-Ng and Ng levels were not significantly different between the C2 and C3 groups, suggesting that the behavioral testing did not affect Ng levels. Our findings suggest that a single swim stress may have short-term benefits for $\mathrm{Ng}$ synthesis and utilization in the brain.

The exact reasons for differences in Ng levels between CS and AS animals are unclear. Interestingly, differences between the effects of acute and chronic stress also have been reported for physiological responses [9] [37] [44]. Chronic, but not acute stress, causes shortening and debranching of dendrites in the CA3 region of the hippocampus and suppresses neurogenesis of dentate gyrus granule neurons [35]. Previous studies have found marked reductions in CA3 apical dendrites following a number of chronic stressors including foot shock stress, restraint stress, cold stress, swim stress, and social stress [1] [34] [45].

These forms of structural remodeling are mediated by glucocorticoid mechanisms working in concert with excitatory amino acids [1] [34] [45]. Several studies have found an association between $\mathrm{Ng}$ and dendritic morphology. Ng was localized in dendritic spines of pyramidal neurons in the hippocampus and prefrontal cortex [17] [18], and Ng immunostaining is an alternative method for investigating dendritic pathology [46]. However, we did not determine dendritic morphology in the hippocampus or prefrontal cortex following either repeated or acute swim stress in the present study. Thus, to test the hypothesis that the decreased Ng levels observed in our CS animals result from dendritic alterations, it will be important for future studies to directly examine dendritic morphology with immunohistochemical methods.

\subsection{Ng Involvement in Stress-Induced Depression and Anxiety}

Chronic exposure to swim stress in rats induced depression-like behaviors and decreased Ng levels. Deceased Ng levels in the hippocampus were positively correlated with saccharine intake, suggesting a relationship between $\mathrm{Ng}$ with this depression-like behavior. We believe that inhibition of $\mathrm{Ng}$ synthesis might be one of the mechanisms underlying stress-related depression. The cascade of signaling events triggered by cAMP has been suggested to play a pivotal role in depression pathogenesis [47] [48]. Chronic treatment with antidepressants or electroconvulsive shock therapy potentiates the downstream effects of cAMP signaling, including specific transcription factors (e.g., CREB and BDNF) that regulate neuroprotection and neuroplasticity [48]. Recently, Ngnull mice were found to show decreased CREB phosphorylation [29]. Downregulation of Ng in the hippocampus decreased PKC activation and altered $\mathrm{Ca}^{2+} / \mathrm{CaM}$-signaling pathways [27]. Given the crucial role of $\mathrm{Ng}$ and $\mathrm{P}-\mathrm{Ng}$ in regulation of numerous signal transduction pathways, stress-induced Ng reductions in selected brain areas may contribute to depression by altering signaling, impairing synaptic plasticity, and/or enhancing cognitive decline [49].

Decreased Ng levels were inversely correlated with grooming behavior, also suggesting a relationship between Ng and anxiety-like behavior. Previous studies support decreased Ng levels in anxiety-like behavior: Ng knockout mice exhibit anxiety-like tendencies in the light-dark exploration test and in time spent in center of an open field [26]. Clinical studies have found that depression is the most common psychiatric illness associated with anxiety and common mechanisms are involved in anxiety and depression [4]. Our findings that decreased $\mathrm{Ng}$ is correlated with both depression- and anxiety-like behaviors suggest that Ng may be the common neurobiological substrate in anxiety and depression pathogenesis.

Acute stress (i.e., single forced swim stress) increased immobility and P-Ng and Ng levels. Further, P-Ng in the prefrontal cortex was positively correlated with immobility. Acute foot shock stress was found to increase immobility in open field and this effect could be attenuated by anxiolytic administration [50]. Pijlman et al. [42] interpreted immobility as a coping strategy in response to acute stress. Although the swim stress and open field environments were not identical in the present study, they may be similar enough to induce an immobility "coping” response in AS animals.

In animals, several behavioral parameters are considered signs of anxiety: increased immobility, increased grooming, and decreased ambulation [40] [41]. However, more horizontal ambulation and less grooming caused 
by large open field could also be considered as fear-like behaviors [51]; thus, the physiological bases of these behavioral responses may be different. The correlation between P-Ng and immobility suggests that increased phosphorylation of Ng could mediate increased anxiety in AS animals; however, this finding was not observed in CS animals. Interestingly, this finding suggests that acute stress enhanced several neurobiological responses associated with increased anxiety.

Here we show that Ng may be the neurobiological substrate mediating the effects of stress on mood. To our knowledge, this is the first report demonstrating a relationship between $\mathrm{Ng}$ and stress-induced behavioral disorders. Although a targeted therapy might be difficult to apply clinically, our findings suggest that induction of $\mathrm{Ng}$ could play a pivotal role in depression therapy. The role of $\mathrm{Ng}$ in depression and anxiety symptomatology, however, remains to be elucidated.

Similar to previous studies, rats in our study were individually housed [9] [38]; thus, possible effects of social isolation on behavior and Ng levels need to be considered. Differences between group-housed and isolated animals have been found in the social interaction test [52]. Niesink and Van Ree [53] described increased social interaction in rats following a short isolation. Wilson [54] reported that the presence of another animal altered the perception of an aversive situation and reduced stress. It is possible that the behavioral responses and altered $\mathrm{Ng}$ levels in our study were caused by the combination of swim and social isolation stress; however, no differences were found between baseline behavior and behavior after 14 days of isolation housing in control animals. Social isolation may have increased vulnerability to swim stress-induced behavioral disorders. Future studies should include group-housed animals to control for the potential effects of social isolation on behavior and $\mathrm{Ng}$ levels.

\section{Conclusion}

In summary, CS produced depression- and anxiety-like behaviors and decreased Ng levels in the hippocampus and prefrontal cortex. Ng levels in the hippocampus were correlated with both depression- and anxiety-like behaviors. AS induced anxiety-like behavior and increased P-Ng and Ng levels in the hippocampus and prefrontal cortex. P-Ng in the prefrontal cortex was correlated with anxiety-like behavior. Our data suggest that CS and AS differentially affect depression- and anxiety-like behaviors and Ng levels in rats. Ng dysfunction might contribute to the neural mechanisms underlying stress-induced depression and anxiety.

\section{Acknowledgements}

This research was supported by the research grants from the National Science Foundation of China (NSF30370482; NSF84201120), and a grant from the innovational project of the Chinese Academy of Sciences (KSCX2-2-03).

\section{References}

[1] Blanchard, R.J., Mckittrick, C.R. and Blanchard, D.C. (2001) Animal Models of Social Stress: Effects on Behavior and Brain Neurochemical Systems. Physiology \& Behavior, 73, 261-271. http://dx.doi.org/10.1016/S0031-9384(01)00449-8

[2] Palanza, P. (2001) Animal Models of Anxiety and Depression: How Are Female Different? Neuroscience \& Biobehavioral Reviews, 25, 219-223. http://dx.doi.org/10.1016/S0149-7634(01)00010-0

[3] Matuzany-Ruban, A., Schreiber, G., Farkash, P. and Avissar, S. (2006) Phosducin-Like Protein Levels in Leukocytes of Patients with Major Depression and in Rat Cortex: The Effect of Chronic Treatment with Antidepressants. Psychiatry Research, 141, 287-294. http://dx.doi.org/10.1016/j.psychres.2005.09.009

[4] Paul, S.M. (1988) Anxiety and Depression: A Common Neurobiological Substrate? The Journal of Clinical Psychiatry, 49, 13-16.

[5] Anand, K.J. and Scalzo, F.M. (2000) Can Adverse Neonatal Experiences Alter Brain Development and Subsequent Behavior? Biology of the Neonate, 77, 69-82. http://dx.doi.org/10.1159/000014197

[6] Bremner, J.D. (2002) Structural Changes in the Brain in Depression and Relationship to Symptom Recurrence. CNS Spectrosc, 7, 135-139.

[7] McEwen, B.S. (2000) Effects of Adverse Experiences for Brain Structure and Function. Biological Psychiatry, 48, 721-731. http://dx.doi.org/10.1016/S0006-3223(00)00964-1

[8] McEwen, B.S. (2001) Stress, Sex, Hippocampal Plasticity: Relevance to Psychiatric Disorders. Clinical Neuroscience Research, 1, 19-34. http://dx.doi.org/10.1016/S1566-2772(00)00004-9 
[9] Qi, X.L., Lin, W.J., Li, J.F., Pan, Y.Q. and Wang, W.W. (2006) The Depressive-Like Behaviors Are Correlated with Decreased Phosphorylation of Mitogen-Activated Protein Kinases in Rat Brain Following Chronic Forced Swim Stress. Behavioural Brain Research, 175, 233-240. http://dx.doi.org/10.1016/j.bbr.2006.08.035

[10] Winder, D.G. and Schremm, N.L. (2001) Plasticity and Behavior: New Genetic Techniques to Address Multiple Forms and Functions. Physiology \& Behavior, 73, 763-780. http://dx.doi.org/10.1016/S0031-9384(01)00514-5

[11] Pasinelli, P., Ramakers, G.M.J., Urban, I.J.A., Hens, J.J.H., Oestreicher, A.B., de Graan, P.N.E. and Gispen, W.H. (1995) Long-Term Potentiation and Synaptic Protein Phosphorylation. Behavioural Brain Research, 66, 53-59. http://dx.doi.org/10.1016/0166-4328(94)00124-X

[12] Filipovic, D., Gavrilovic, L., Dronjak, S. and Radojcic, M.B. (2005) Brain Glucocorticoid Receptor and Heat Shock Protein 70 Levels in Rats Exposed to Acute, Chronic or Combined Stress. Neuropsychobiology, 51, 107-114. http://dx.doi.org/10.1159/000084168

[13] Grønli, J., Bramham, C., Murison, R., Kanhema, T., Fiske, E., Bjorvatn, B., Ursin, R. and Portas, C.M. (2006) Chronic Mild Stress Inhibits BDNF Protein Expression and CREB Activation in the Dentate Gyrus but Not in the Hippocampus Proper. Pharmacology Biochemistry and Behavior, 85, 842-849. http://dx.doi.org/10.1016/j.pbb.2006.11.021

[14] Mengesdorf, T., Proud, C.G., Mies, G. and Paschen, W. (2002) Mechanisms Underlying Suppression of Protein Synthesis Induced by Transient Focal Cerebral Ischemia in Mouse Brain. Experimental Neurology, 177, 538-546. http://dx.doi.org/10.1006/exnr.2002.8002

[15] Pae, C.U., Mandelli, L., Serretti, A., Patkar, A.A., Kim, J.J., Lee, C.U., Lee, S.J., Lee, C., Ronchi, D.D. and Paik, I.H. (2007) Heat-Shock Protein-70 Genes and Response to Antidepressants in Major Depression. Progress in Neuro-Psychopharmacology and Biological Psychiatry, 31, 1006-1011. http://dx.doi.org/10.1016/j.pnpbp.2007.02.011

[16] Bilang-Bleue, A., Rech, J., De Carli, S., Holsboer, F. and Reul, J.M. (2002) Forced Swimming Evokes a Biphasic Response in CREB Phosphorylation in Extrahypothalamic Limbic and Neocortical Brain Structure in the Rat. European Journal of Neuroscience, 15, 1048-1060. http://dx.doi.org/10.1046/j.1460-9568.2002.01934.x

[17] Houben, M.P., Lankhorst, A.J., van Dalen, J.J., Veldman, H., Joosten, E.A., Hamers, F.P., Gispen, W.H. and Schrama, L.H. (2000) Pre- and Postsynaptic Localization of RC3/Neurogranin in the Adult Rat Spinal: An Immunohistochemical Study. Journal of Neuroscience Research, 59, 750-759. http://dx.doi.org/10.1002/(SICI)1097-4547(20000315)59:6<750::AID-JNR7>3.0.CO;2-B

[18] Watson, J.B., Sutcliffe, J.G. and Fisher, R.S. (1992) Localization of the Protein Kinase C Phosphorylation/CalmodulinBinding Substrate RC3 in Dendritic Spines of Neostriatal Neurons. Proceedings of the National Academy of Sciences of the United States of America, 89, 8581-8585. http://dx.doi.org/10.1073/pnas.89.18.8581

[19] Huang, K.P., Freesia, L., Li, J.F., Schuck, P. and McPhie, P. (2000) Calcium-Sensitive Interaction between Calmodulin and Modified Forms of Rat Brain Neurogranin/RC3. Biochemistry, 39, 7291-7299. http://dx.doi.org/10.1021/bi0003361

[20] Pak, J.H., Huang, F.L., Li, J., Balschun, D., Reymann, K.G., Chiang, C., Westphal, H. and Huang, K.P. (2000) Involvement of Neurogranin in the Modulation of Calcium/Calmodulin-Dependent Protein Kinase II, Synaptic Plasticity, and Spatial Learning: A Study with Knockout Mice. Proceedings of the National Academy of Sciences of the United States of America, 97, 11232-11237. http://dx.doi.org/10.1073/pnas.210184697

[21] Chakravarthy, B., Morley, P. and Whitfield, J. (1999) $\mathrm{Ca}^{2+}$-Calmodulin and Protein Kinase Cs: A Hypothetical Synthesis of Their Conflicting Convergences on Shared Substrate Domains. Trends in Neurosciences, 22, 12-16. http://dx.doi.org/10.1016/S0166-2236(98)01288-0

[22] Mattson, M.P., LaFerla, F., Chan, S.L., Leissring, M.A., Shepel, P.N. and Geiger, J.D. (2000) Calcium Signaling in the ER: Its Role in Neuronal Plasticity and Neurodegenerative Disorders. Trends in Neurosciences, 23, 222-229. http://dx.doi.org/10.1016/S0166-2236(00)01548-4

[23] Wang, H., Hu, Y. and Tsien, J.Z. (2006) Molecular and Systems Mechanisms of Memory Consolidation and Storage. Progress in Neurobiology, 79, 123-135. http://dx.doi.org/10.1016/j.pneurobio.2006.06.004

[24] Fedorov, N.B., Pasinelli, P., Oestreicher, A.B., DeGraan, P.N. and Reymann, K.G. (1995) Antibodies to Postsynaptic PKC Substrate Neurogranin Prevent Long-Term Potentiation in Hippocampal CA1 Neurons. European Journal of Neuroscience, 7, 819-822. http://dx.doi.org/10.1111/j.1460-9568.1995.tb00685.x

[25] Chang, J.W., Schumacher, E., Coulter, P.M., Vinters, H.V. and Watson, J.B. (1997) Dendritic Translocation of RC3/Neurogranin mRNA in Normal Aging, Alzheimer Disease and Fronto-Temporal Dementia. Journal of Neuropathology \& Experimental Neurology, 56, 1105-1118. http://dx.doi.org/10.1097/00005072-199710000-00004

[26] Miyakawa, T., Yared, E., Pak, J.H., Huang, F.L., Huang, K.P. and Crawley, J.N. (2001) Neurogranin Null Mutant Mice Display Performance Deficits on Spatial Learning Tasks with Anxiety Related Components. Hippocampus, 11, 763-775. http://dx.doi.org/10.1002/hipo.1092

[27] Shukla, P.K., Tang, L. and Wang, Z.J. (2006) Phosphorylation of Neurogranin, Protein Kinase C, and Ca2+/Calmudulin Dependent Protein Kinase II in Opioid Tolerance and Dependence. Neuroscience Letters, 404, 266-269. 
[28] Ruano, D., Aulchenko, Y.S., Macedo, A., Soares, M.J., Valente, J., Azevedo, M.H., Hutz, M.H., Gama, C.S., Lobato, M.I., Belmonte-de-Abreu, P., Goodman, A.B., Pato, C., Heutink, P. and Palha, J.A. (2006) Association of the Gene Encoding Neurogranin with Schizophrenia in Males. Journal of Psychiatric Research, 42, 125-133.

[29] Wu, J., Li, J., Huang, K.P. and Huang, F.L. (2002) Attenuation of Protein Kinase C and cAMP-Dependent Protein Kinase Signal Transduction in the Neurogranin Knockout Mouse. Journal of Biological Chemistry, 277, 19498-19505. http://dx.doi.org/10.1074/jbc.M109082200

[30] Neuner-Jehle, M., Rhyner, T.A. and Borbely, A.A. (1995) Sleep Deprivation Differentially Alters the mRNA and Protein Levels of Neurogranin in Rat Brain. Brain Research, 685, 143-153. http://dx.doi.org/10.1016/0006-8993(95)00416-N

[31] Chen, C.C. (1994) Alterations of Protein Kinase C Isozyme and Substrate Proteins in Mouse Brain after Electroconvulsive Seizures. Brain Research, 648, 65-72. http://dx.doi.org/10.1016/0006-8993(94)91906-2

[32] Li, H., Li, Q.H., Zhu, Z.L., Chen, R., Cheng, D.X., Cai, Q., Jia, N. and Song, L. (2007) Prenatal Restraint Stress Decreases Neurogranin Expression in Rat Offspring Hippocampus. Acta Physiologica Sinica, 59, 299-304. (In Chinese)

[33] Mizoguchi, K., Isgige, A., Aburada, M. and Tabira, T. (2003) Chronic Stress Attenuates Glucocorticoid Negative Feedback: Involvement of the Prefrontal Cortex and Hippocampus. Neuroscience, 119, 887-897. http://dx.doi.org/10.1016/S0306-4522(03)00105-2

[34] Daenen, E.W., Van der Heyden, J.A., Kruse, C.G., Wolterink, G. and Van Ree, J.M. (2001) Adaptation and Habituation to an Open Field and Response to Various Stressful Events in Animals with Neonatal Lesions in the Amygdala or Ventral Hippocampus. Brain Research, 918, 153-165. http://dx.doi.org/10.1016/S0006-8993(01)02987-0

[35] Vyas, A., Mitra, R., Shankaranarayana Rao, B.S. and Chattarji, S. (2002) Chronic Stress Induces Contrasting Patterns of Dendritic Remodeling in Hippocampal and Amygdaloid Neurons. Journal of Neuroscience, 22, 6810-6818.

[36] Coryell, W., Nopoulos, P., Drevets, W., Wilson, T. and Andreasen, N.C. (2005) Subgenual Prefrontal Cortex Volumes in Major Depressive Disorder and Schizophrenia: Diagnostic Specificity and Prognostic Implications. American Journal of Psychiatry, 162, 1706-1712. http://dx.doi.org/10.1176/appi.ajp.162.9.1706

[37] Dal-Zotto, S., Marti, O. and Armario, A. (2000) Influence of Single or Repeated Experience of Rats with Forced Swimming on Behavioural and Physiological Responses to the Stressor. Behavioural Brain Research, 114, 175-181. http://dx.doi.org/10.1016/S0166-4328(00)00220-5

[38] Blustein, J.E., Ciccolone, L. and Bersh, P.J. (1998) Evidence that Adaptation to Cold Water Swim-Induced Analgesia Is a Learned Response. Physiology \& Behavior, 63, 147-150. http://dx.doi.org/10.1016/S0031-9384(97)00382-X

[39] Paxinos, G. and Watson, C.R. (1998) The Rat Brain in Stereotaxic Coordinate. 4th Edition, Academic Press, New York.

[40] Ducottet, C. and Belzung, C. (2004) Behaviour in the Elevated Plus-Maze Predicts Coping after Subchronic Mild Stress in Mice. Physiology \& Behavior, 81, 417-426. http://dx.doi.org/10.1016/j.physbeh.2004.01.013

[41] Kalueff, A.V. and Tuohimaa, P. (2005) The Grooming Analysis Algorithm Discriminates between Different Levels of Anxiety in Rats: Potential Utility for Neurobehavioral Stress Research. Journal of Neuroscience Methods, 143, 169-177. http://dx.doi.org/10.1016/j.jneumeth.2004.10.001

[42] Pijlman, F.T.A. and Van Ree, J.M. (2002) Physical but Not Emotional Stress Induces a Delay in Behavioural Coping Responses in Rats. Behavioural Brain Research, 136, 365-373. http://dx.doi.org/10.1016/S0166-4328(02)00128-6

[43] Sareen, J., Cox, B.J., Stein, M.B., Afifi, T.O., Fleet, C. and Asmundson, G.J. (2007) Physical and Mental Comorbidity, Disability, and Suicidal Behavior Associated with Posttraumatic Stress Disorder in a Large Community Sample. Psychosomatic Medicine, 69, 242-248. http://dx.doi.org/10.1097/PSY.0b013e31803146d8

[44] Shen, C.P., Tsimberg, Y., Salvadore, C. and Meller, E. (2004) Activation of Erk and JNK MAPK Pathways by Acute Swim Stress in Rat Brain Regions. BMC Neuroscience, 5, 36.

[45] Fuchs, E. and Flugge, G. (2003) Chronic Social Stress: Effects on Limbic Brain Structures. Physiology \& Behavior, 79, 417-427. http://dx.doi.org/10.1016/S0031-9384(03)00161-6

[46] Li, G.L., Farooque, M., Lewen, A., Lennmyr, F., Holtz, A. and Olsson, Y. (2000) MAP2 and Neurogranin as Markers for Dendritic Lesions in CNS Injury. An Immunohistochemical Study in the Rat. APMIS, 108, 98-106. http://dx.doi.org/10.1034/j.1600-0463.2000.d01-32.x

[47] Aydemir, O., Deveci, A. and Taneli, F. (2005) The Effect of Chronic Antidepressant Treatment on Serum Brain-Derived Neurotrophic Factor Levels in Depressed Patients: A Preliminary Study. Progress in Neuro-Psychopharmacology and Biological Psychiatry, 29, 261-265. http://dx.doi.org/10.1016/j.pnpbp.2004.11.009

[48] Itoh, T., Tokumura, M. and Abe, K. (2004) Effects of Rolipram, a Phosphodiesterase 4 Inhibitor, in Combination with Imipramine on Depressive Behavior, CRE-Binding Activity and BDNF Level in Learned Helplessness Rats. European Journal of Pharmacology, 498, 135-142. http://dx.doi.org/10.1016/j.ejphar.2004.07.084 
[49] Mons, N., Enderlin, V., Jaffard, R. and Higueret, P. (2001) Selective Age-Related Changes in the PKC-Sensitive, Calmodulin-Binding Protein, Neurogranin, in the Mouse Brain. Journal of Neurochemistry, 79, 859-867. http://dx.doi.org/10.1046/j.1471-4159.2001.00646.x

[50] Bruijnzeel, A.W., Stam, R. and Wiegant, V.M. (2001) Effect of a Benzodiazepine Receptor Agonist and CRH Receptor Antagonist on Long-Term Foot Shock-Induced Increase in Defensive Withdrawal Behavior. Psychopharmacology, 158, 132-139. http://dx.doi.org/10.1007/s002130100863

[51] Morrow, B.A., Elsworth, J.D. and Roth, R.H. (2002) Fear-Like Biochemical and Behavioral Responses in Rats to the Predator Odor, TMT, Are Dependent on the Exposure Environment. Synapse, 46, 11-18. http://dx.doi.org/10.1002/syn.10109

[52] Sams-Dodd, F. (1995) Automation of the Social Interaction Test by a Video-Tracking System: Behavioural Effects of Repeated Phencyclidine Treatment. Journal of Neuroscience Methods, 59, 157-167. http://dx.doi.org/10.1016/0165-0270(94)00173-E

[53] Niesink, R.J. and Van Ree, J.M. (1982) Short-Term Isolation Increases Social Interactions of Male Rats: A Parametric Analysis. Physiology \& Behavior, 29, 819-825. http://dx.doi.org/10.1016/0031-9384(82)90331-6

[54] Wilson, J.H. (2000) A Conspecific Attenuates Prolactin Responses to Open-Field Exposure in Rats. Hormones and Behavior, 38, 39-43. http://dx.doi.org/10.1006/hbeh.2000.1600 
Scientific Research Publishing (SCIRP) is one of the largest Open Access journal publishers. It is currently publishing more than 200 open access, online, peer-reviewed journals covering a wide range of academic disciplines. SCIRP serves the worldwide academic communities and contributes to the progress and application of science with its publication.

Other selected journals from SCIRP are listed as below. Submit your manuscript to us via either submit@scirp.org or Online Submission Portal.
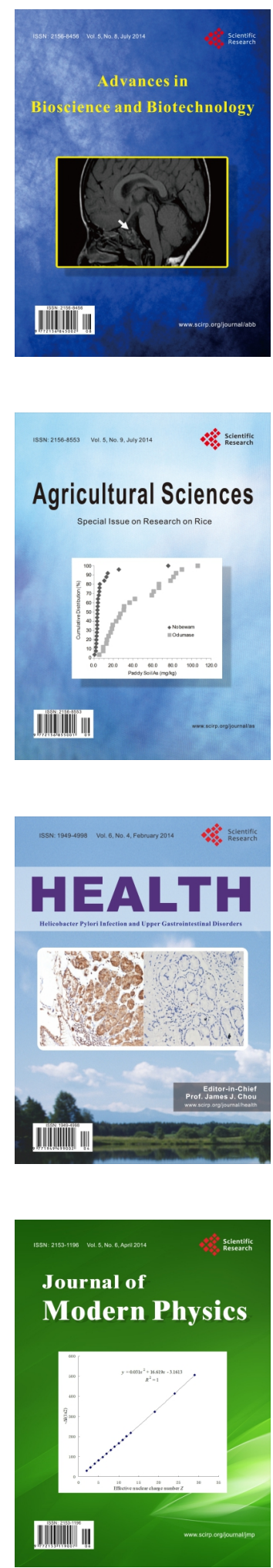
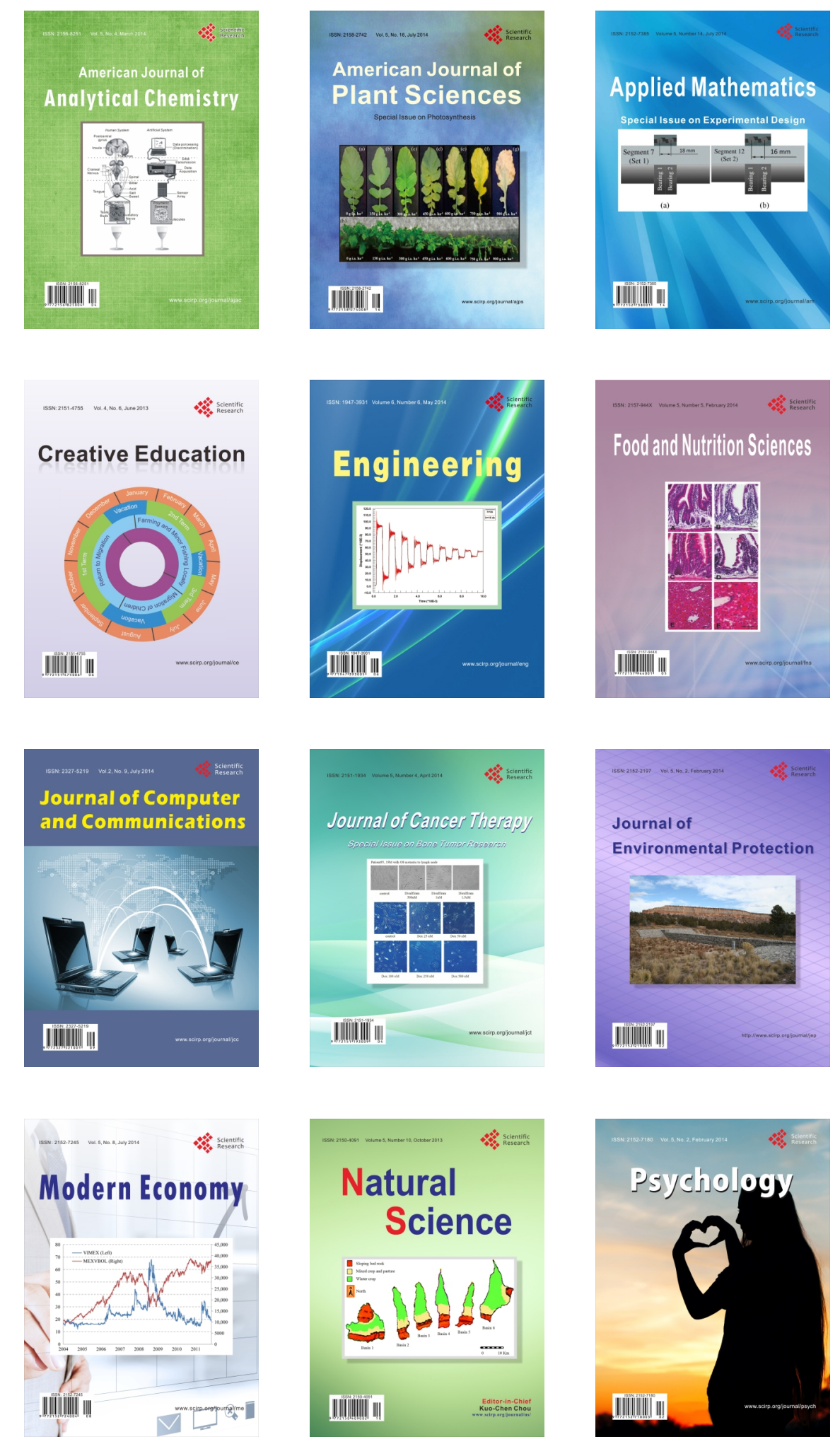